\title{
Durabilidade de concretos com agregados reciclados: uma aplicação de análise hierárquica
}

\author{
Durability of recycled aggregate concrete: an analytical \\ hierarchy process application
}

\begin{abstract}
Eduardo Pereira
Marcelo Henrique Farias de Medeiros

Salomon Mony Levy

Resumo

preocupação com a destinação dos resíduos de demolição de 1 construções e a escassez de materiais naturais para a produção de 1 agregados têm motivado a realização de estudos sobre o reaproveitamento dos resíduos da construção em diferentes países. O presente trabalho discute o uso combinado de agregados reciclados de construção e demolição e agregados naturais, para se obter resistências adequadas do concreto, enfatizando a durabilidade dos elementos estruturais executados. A contribuição principal deste estudo foi o emprego da Análise Hierárquica (AHP), para comparar o nível de desempenho das opções consideradas. Essa técnica baseia-se na identificação dos elementos-chave para a tomada de decisão na definição de prioridades e na consistência lógica do modelo de priorização construído. Foram incluídos no estudo treze traços de concreto (um de referência mais doze variações de teores de agregados reciclados) para cada um dos três níveis de resistência à

Eduardo Pereira Departamento de Construção Civil, Centro Politécnico

Universidade Federal do Paraná

$J$ ardim das Américas

Caixa Postal 19011

Curitiba - PR - Brasil

CEP 81531-980

Tel.: (41) 3361-3364

E-mail:

engenheiroeduardopereira@gmail.com

Marcelo Henrique Farias de

Medeiros

Departamento de Construção Civil,

Centro Politécnico

Universidade Federal do Paraná

E-mail: medeiros.ufpr@gmail.com

Salomon Mony Levy Departamento de Ciências Exatas e
Tecnologia

Universidade Nove de J ulho

Rua Dr. Adolfo Pinto, 109 Barra Funda

São Paulo - SP - Brasil

Tel.: (11) 3665-9000

E-mail: 123.salomon@gmail.com

Recebido em 06/10/11

Aceito em 26/05/12

compressão de dosagem considerados (20, 30 e $40 \mathrm{MPa}$ ), totalizando 39

proporcionamentos de concretos. Essas variações foram avaliadas utilizando-se oito parâmetros, e o emprego da AHP teve o objetivo de proporcionar uma avaliação global dos casos estudados. A Análise Hierárquica mostrou-se eficaz no auxílio à tomada de decisões na dosagem do concreto com agregados reciclados.

Palavras-chave: Análise hierárquica. Concreto. Agregados reciclados. Durabilidade.

\section{Abstract}

The concern about the disposal of waste from the demolition of buildings and the scarcity of natural materials for the production of aggregates have motivated the realization of studies on the reuse of construction waste in different countries. This paper discusses the combined use of recycled aggregates from construction and demolition waste and natural aggregates in order to obtain suitable concrete strengths, emphasizing the durability of the structural elements produced. The main contribution of this paper is the use of hierarchical analysis to compare the performance of the options considered. This technique is based on identifying the key elements for decision-making in setting priorities and on the logical consistency of the model to be built. Thirteen concrete mix proportions were included in the study (one reference plus twelve different levels of recycled aggregate) for each of the three levels of compressive strength considered (20, 30 and $40 \mathrm{MPa}$ ), totaling 39 mix proportions. These variations were evaluated using eight parameters and applying AHP for the purpose of providing a comprehensive assessment of the cases studied. The Analytical Hierarchy tool was effective in supporting decision-making in the process of designing concrete mix with recycled aggregates.

Keywords: Analytical hierarchy process. Concrete. Recycled aggregates. Durability.
\end{abstract}




\section{Introdução}

A preocupação com o impacto gerado pela produção de resíduos provenientes da construção civil e a perspectiva de aumento no número de demolições têm gerado estudos em vários países quanto às possibilidades de reaproveitamento desses resíduos como agregados. A substituição dos agregados convencionais por agregados reciclados apresenta diversas vantagens, como economia na aquisição de matéria-prima, diminuição da poluição gerada pela produção dos agregados e melhora na preservação das reservas naturais de matéria-prima do planeta.

As características dos resíduos usados influenciam muitas das propriedades do concreto com agregados reciclados. Isso já foi comprovado por diversas pesquisas (LEITE, 2001; AWASTHI; CHAUHAN, 2011; VIDAL et al., 2010; ISSAI et al., 2011), e as alterações podem ser percebidas tanto no estado fresco como no estado endurecido do concreto moldado a partir de resíduos (HANSEN, 1992). Tam, Tam e Wang (2006) citam que as características inerentes ao agregado reciclado, incluindo alta porosidade e elevado nível de impurezas, afetam a resistência mecânica de concretos produzidos com esses materiais e limitam suas aplicações. Atualmente, no Brasil, a aplicação mais comum de agregados de concreto reciclado ocorre em sub-base de pavimentos, no entanto, quando atingidas certas propriedades, a utilização pode ocorrer em qualquer situação (PINTO, 1999).

Hansen (1992) apresentou resultados de combinações de agregados reciclados tanto miúdos quanto graúdos. Os concretos nos quais foi usada somente a fração graúda do agregado reciclado apresentaram diminuição de apenas 5\% no valor da resistência à compressão em relação ao concreto com agregados naturais. Para uma substituição total, ou seja, a utilização de frações miúda e graúda, tal redução chegou a valores entre $20 \%$ e 40\%. Quando adotada uma substituição parcial, em que existe na fração miúda uma composição de 50\% de material natural (areia) e $50 \%$ de agregado reciclado, a redução ficou entre $10 \%$ e $20 \%$.

Vieira, Dal Molin e Lima (2004) verificaram que, quanto menor a relação água-cimento (a/c) e maior o percentual de substituição dos agregados graúdos reciclados, menores foram as resistências. $\mathrm{O}$ autor atribui essa diminuição à baixa resistência e densidade dos grãos do agregado reciclado e também à maior demanda de água por parte desses agregados para obter-se determinada trabalhabilidade, sendo esse efeito mais pronunciado em agregados com baixas relações a/c.

Alguns estudos têm sido realizados para melhor compreender os efeitos do agregado reciclado no concreto ante sua durabilidade. De acordo com Evangelista e Brito (2010), a migração de cloretos tende a aumentar com a elevação na substituição de agregados reciclados finos, e em alguns casos esse incremento chega a 34\% para o concreto com total substituição em comparação com o concreto de referência. Vieira, Dal Molin e Lima (2004) afirmam que o efeito do uso de agregado reciclado no potencial de corrosão é tão menor quando menor a relação a/c utilizada. Essa é uma área de pesquisa que precisa ainda ser mais bem explorada, principalmente no Brasil, pois a utilização de concretos com agregados reciclados só irá ganhar espaço no mercado quando conhecermos muito bem sua durabilidade em comparação com o concreto convencional.

O objetivo principal deste trabalho é apresentar a ferramenta Analytic Hierarchy Process (AHP), ou simplesmente Análise Hierárquica, utilizada para a tomada de decisões de forma sistêmica, considerando um conjunto de parâmetros interpretados de forma global. Essa ferramenta de gerenciamento foi utilizada nesta pesquisa para auxiliar a fundamentar a seleção de concretos com a incorporação de agregados reciclados, buscandose reduzir o impacto ambiental gerado pela indústria do concreto e, ao mesmo tempo, garantir uma durabilidade mínima para os materiais.

Com base no exposto anteriormente e utilizando-se dados obtidos da tese de doutorado de Levy (2001), este trabalho discute, a partir da Análise Hierárquica, combinações entre agregados reciclados de construções e demolições e agregados naturais, para obterem-se determinadas resistências do concreto, com vistas à durabilidade dos elementos estruturais executados.

\section{Aplicação de análise hierárquica}

Uma escolha ou tomada de decisão apresenta a necessidade de avaliação de um conjunto de alternativas. Todos os dias, naturalmente, nosso cérebro decide entre inúmeras opções utilizando uma série de critérios predefinidos, sem que nos preocupemos com esse processo. Um exemplo é o caminho a percorrer até determinado ponto. Muitas vezes a menor distância não é o único critério que adotamos; também podemos decidir em função de 
segurança no trajeto, provável presença de congestionamentos, etc.

Com base nessa ideia, Saaty, no início dos anos 1970, desenvolveu uma técnica chamada Analytic Hierarchy Process (AHP) ou simplesmente Análise Hierárquica (COSTA, 2002). O AHP é um dos mais conhecidos métodos de tomada de decisões, sendo utilizado por vários autores como ferramenta de gerenciamento. A técnica está apoiada em três princípios básicos do pensamento analítico:

(a) construção hierárquica, pela qual são identificados os elementos-chave para a tomada de decisão;

(b) definição de prioridades; e

(c) consistência lógica do modelo de priorização construído.

A etapa de definição do objetivo que se quer alcançar com a aplicação da AHP é de suma importância para obter-se um modelo adequado. Neste trabalho o objetivo é verificar qual a melhor combinação, em porcentagem de mistura entre agregados reciclados e agregados naturais, para obter-se um concreto com dada resistência, apoiado em critérios que visem à durabilidade das estruturas de concreto executadas com esses traços. O segundo ponto da AHP consiste na identificação das alternativas, sendo sempre necessário estabelecerem-se alternativas viáveis. A Tabela 1 apresenta um resumo das combinações usadas neste trabalho para o estudo da durabilidade de concretos produzidos com substituições de agregados naturais por agregados reciclados de concreto (RC) e de alvenaria (RA), tanto nas frações graúdas $(G)$ quanto nas frações miúdas (M).
Após a escolha das alternativas, estabeleceu-se o conjunto de critérios a ser considerado na modelagem do problema, de tal forma que o modelo aproxime-se o máximo possível da realidade, com níveis mínimos de abstração (COSTA, 2002). Os critérios considerados na modelagem desta AHP constam na Tabela 2. Com vistas à durabilidade de concretos produzidos com agregados reciclados, Levy (2001) analisou oito quesitos, sendo eles utilizados aqui para aplicação da Análise Hierárquica. É importante enfatizar que os dados usados como pano de fundo neste trabalho foram obtidos por Levy (2001) a partir de dosagens de famílias de concretos empregando o método de dosagem clássico no Brasil, também conhecido como método IPT/EPUSP, detalhado por Helene e Terzian (1993). A contribuição deste artigo é basicamente a utilização da técnica de AHP para fundamentar a escolha da(s) melhor(es) opção(ões) entre as 13 possibilidades constantes no trabalho de Levy (2001).

Neste trabalho não se utilizaram quesitos qualitativos, porém, caso fossem adotados, deverse-ia criar uma escala numérica para quantificar a propriedade qualitativa e assim proceder-se normalmente à AHP.

Um exemplo de presença de quesitos qualitativos dentro de uma Análise Hierárquica é a compra de um carro. Entre as variáveis possíveis para auxílio na decisão, como custo e economia de combustível, está a cor. Suponha-se que a preferência seja por carros pretos. Observa-se que a cor não pode ser quantificável. Então, para decidir entre um carro de cor preta e um de cor branca, pode-se atribuir peso 2 para a cor preta e 1 para a cor branca, ou mesmo peso 1 para o carro preto e 0 para o carro branco, ou seja, atribuir um valor a um critério qualitativo.

Tabela 1 - Combinações entre agregados reciclados e agregados naturais (\%)

\begin{tabular}{c|c}
\hline Agregado reciclado - natural (\%) & Agregado reciclado-natural (\%) \\
\hline $1^{\text {a }}$ Referência 0-100 & $8^{\text {a }}$ RAG 20-80 \\
$2^{\text {a }}$ RCG 20-80 & $9^{\text {a }}$ RAG 50-50 \\
$3^{\text {a }}$ RCG 50-50 & $10^{\text {a }}$ RAG 100-0 \\
$4^{\text {a }}$ RCG 100-0 & $11^{\text {a }}$ RAM 20-80 \\
$5^{\text {a }}$ RCM 20-80 & $12^{\text {a }}$ RAM 50-50 \\
$6^{\text {a }}$ RCM 50-50 & $13^{\text {a }}$ RAM 100-0 \\
$7^{\text {a }}$ RCM 100-0 & \\
\hline
\end{tabular}

Tabela 2 - Critérios de durabilidade usados na AHP

\begin{tabular}{ll|ll}
\hline \multicolumn{1}{c|}{ Propriedades } & \multicolumn{2}{c}{ Propriedades } \\
\hline 1 & Relação água-cimento & 5 & Índice de vazios \\
2 & Consumo de cimento por $\mathrm{m}^{3}$ & 6 & Resistividade \\
3 & Profundidade de carbonatação & 7 & Concentração de cloretos \\
4 & Absorção de água & 8 & Módulo de elasticidade \\
\hline
\end{tabular}


Neste trabalho, após a definição dos critérios, o próximo passo foi focar na escolha entre as opções apresentadas na tabela usando-se a AHP para três patamares de resistência à compressão: $20 \mathrm{MPa}, 30$ $\mathrm{MPa}$ e $40 \mathrm{MPa}$. Os detalhamentos dos procedimentos de avaliação encontram-se nos itens a seguir.

\section{Concretos com $\mathrm{f}_{\mathrm{c} 28 \mathrm{~d}}$ de $20 \mathrm{MPa}$}

Sabendo-se quais as propriedades consideradas na Análise Hierárquica, é necessário estabelecerem-se critérios para o processo de julgamento, uma matriz de decisão. No âmbito do AHP, o avaliador compara par a par os elementos de um nível da análise com vistas a cada um dos elementos presentes em uma camada hierárquica. A norma ASTM E 1765 (AMERICAN..., 2002) apresenta uma escala de julgamentos, que será utilizada (Tabela 3) para expor o método.

Na tentativa de eliminar a subjetividade da análise, optou-se por padronizar todos os critérios como tendo a mesma importância. Essa escolha pode levar a interpretações erradas, porém a influência de cada fator sobre a durabilidade dos concretos não é o foco deste trabalho, sendo necessários estudos mais detalhados sobre o assunto. A Tabela 4 apresenta a matriz de decisão utilizada neste trabalho, indicando que cada parâmetro de avaliação tem peso de $12,5 \%$ na decisão final quanto ao teor de substituição de agregados naturais por reciclados.

Os dados utilizados na Análise Hierárquica estão expostos na Tabela 5.

Nesta etapa, alguns valores precisam ser utilizados ao inverso. Essa manobra permite a padronização dos dados, pois os quesitos analisados são numéricos e, em muitos casos, o valor encontrado é do tipo "quanto maior, pior o desempenho", sendo necessário utilizar-se seu inverso para fazer com que toda a representação numérica seja convertida, de modo que o maior valor corresponda à melhor opção de escolha, agregando coerência à análise. A Tabela 6 apresenta essa etapa de cálculo.

Tabela 3 - Escala de importância

\begin{tabular}{c|c}
\hline \multicolumn{2}{c}{ Escala de importância } \\
\hline Igual & 1 \\
Levemente mais importante & 3 \\
Mais importante & 5 \\
Muito mais importante & 7 \\
Extremamente mais importante & 9 \\
\hline
\end{tabular}

Fonte: ASTM E 1765 (2002).

Tabela 4 - Matriz de decisão da Análise Hierárquica

\begin{tabular}{|c|c|c|c|c|c|c|c|c|c|c|}
\hline Matriz de decisão & & 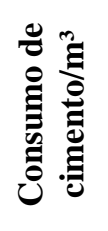 & 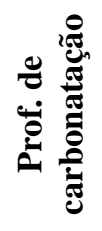 & 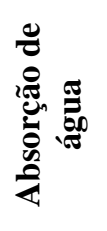 & 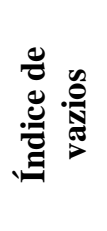 & 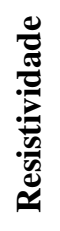 & 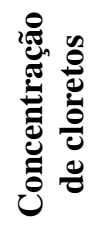 & 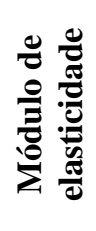 & $\frac{\pi}{\frac{\pi}{0}}$ & 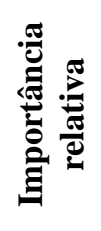 \\
\hline $\begin{array}{l}\text { Relação água- } \\
\text { cimento }\end{array}$ & 1 & 1 & 1 & 1 & 1 & 1 & 1 & 1 & 8 & 0,125 \\
\hline $\begin{array}{l}\text { Consumo de } \\
\text { cimento por } \mathbf{m}^{3}\end{array}$ & 1 & 1 & 1 & 1 & 1 & 1 & 1 & 1 & 8 & 0,125 \\
\hline $\begin{array}{l}\text { Profundidade de } \\
\text { carbonatação }\end{array}$ & 1 & 1 & 1 & 1 & 1 & 1 & 1 & 1 & 8 & 0,125 \\
\hline Absorção de água & 1 & 1 & 1 & 1 & 1 & 1 & 1 & 1 & 8 & 0,125 \\
\hline Índice de vazios & 1 & 1 & 1 & 1 & 1 & 1 & 1 & 1 & 8 & 0,125 \\
\hline Resistividade & 1 & 1 & 1 & 1 & 1 & 1 & 1 & 1 & 8 & 0,125 \\
\hline $\begin{array}{l}\text { Concentração de } \\
\text { cloretos }\end{array}$ & 1 & 1 & 1 & 1 & 1 & 1 & 1 & 1 & 8 & 0,125 \\
\hline $\begin{array}{l}\text { Módulo de } \\
\text { elasticidade }\end{array}$ & 1 & 1 & 1 & 1 & 1 & 1 & 1 & 1 & 8 & 0,125 \\
\hline Total geral & & & & & & & & & 64 & 1 \\
\hline
\end{tabular}

128 Pereira, E.; Medeiros, M. H. F. de; Levy, S. M. 
Tabela 5 - Dados gerais utilizados para construção da AHP para concretos de $20 \mathrm{MPa}$

\begin{tabular}{|c|c|c|c|c|c|c|c|c|c|c|c|c|c|c|}
\hline & \multirow[b]{2}{*}{ Dados gerais de análise } & \multicolumn{13}{|c|}{ Alternativas de escolhas } \\
\hline & & 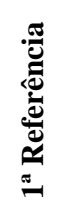 & 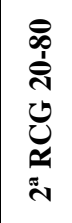 & 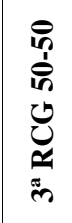 & 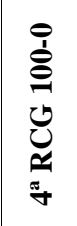 & 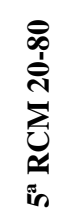 & 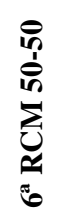 & 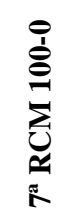 & 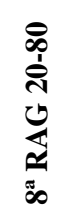 & 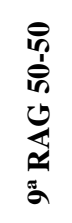 & 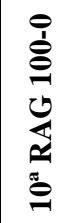 & 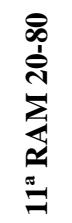 & 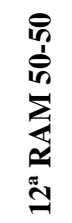 & 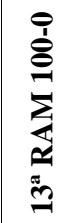 \\
\hline \multirow{8}{*}{ 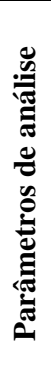 } & Relação água-cimento & 0,91 & 0,79 & 0,85 & 0,93 & 0,95 & 0,89 & 0,90 & 0,80 & 0,92 & 0,87 & 0,86 & 0,95 & 1,03 \\
\hline & $\begin{array}{l}\text { Consumo de cimento por } \\
\text { m }^{3}\end{array}$ & 179 & 269 & 231 & 190 & 200 & 279 & 326 & 239 & 216 & 266 & 220 & 191 & 217 \\
\hline & $\begin{array}{l}\text { Profundidade de } \\
\text { carbonatação }\end{array}$ & 9,6 & 5,5 & 5,0 & 7,7 & 7,0 & 7,6 & 4,3 & 6,0 & 6,5 & 6,7 & 6,4 & 5,8 & 9,0 \\
\hline & Absorção de água & 7,3 & 6,9 & 7,5 & 7,3 & 7,8 & 11,2 & 12,0 & 7,3 & 9,7 & 11,4 & 7,5 & 8,0 & 8,2 \\
\hline & Índice de vazios & 16,0 & 14,5 & 17,5 & 15,3 & 14,9 & 20,4 & 23,1 & 15,8 & 20,2 & 22,9 & 15,9 & 16,7 & 19,0 \\
\hline & Resistividade & 13,3 & 16,3 & 14,8 & 10,1 & 15,6 & 15,4 & 15,0 & 14,2 & 11,7 & 7,2 & 19,3 & 30,6 & 26,6 \\
\hline & Concentração de cloretos & 0,50 & 0,53 & 0,89 & 0,44 & 0,55 & 0,54 & 0,56 & 0,61 & 0,63 & 0,59 & 0,49 & 0,54 & 0,61 \\
\hline & Módulo de elasticidade & 24,2 & 23,5 & 22,8 & 22,5 & 21,3 & 18,7 & 16,0 & 22,0 & 17,3 & 12,6 & 21,9 & 18,8 & 21,0 \\
\hline
\end{tabular}

Nota: resultados numéricos extraídos de Levy (2001).

Tabela 6 - Dados gerais modificados para construção da AHP para concretos de $20 \mathrm{MPa}$

\begin{tabular}{|c|c|c|c|c|c|c|c|c|c|c|c|c|c|c|}
\hline \multirow{2}{*}{\multicolumn{2}{|c|}{$\begin{array}{l}\text { Dados gerais de } \\
\text { análise }\end{array}$}} & \multicolumn{13}{|c|}{ Alternativas de escolhas } \\
\hline & & 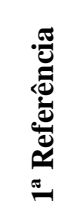 & 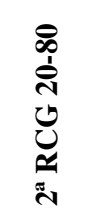 & 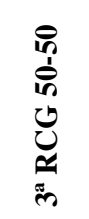 & 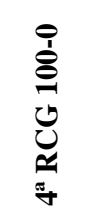 & 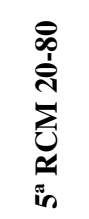 & 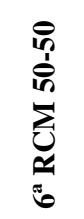 & 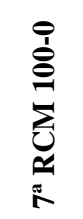 & 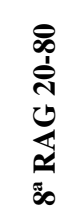 & 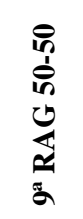 & 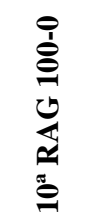 & 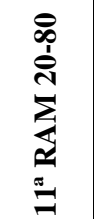 & 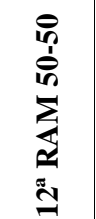 & 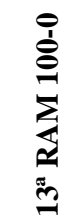 \\
\hline \multirow{8}{*}{ 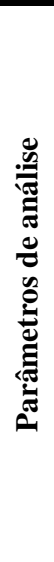 } & $\begin{array}{l}\text { Relação água- } \\
\text { cimento }\end{array}$ & $1 / 0,91$ & $1 / 0,79$ & $1 / 0,85$ & $1 / 0,93$ & $1 / 0,95$ & $1 / 0,89$ & $1 / 0,90$ & $1 / 0,80$ & $1 / 0,92$ & $1 / 0,87$ & $1 / 0,86$ & $1 / 0,95$ & $1 / 1,03$ \\
\hline & $\begin{array}{l}\text { Consumo de } \\
\text { cimento por } \\
\text { m }^{3}\end{array}$ & $1 / 179$ & $1 / 269$ & $1 / 231$ & $1 / 190$ & $1 / 200$ & $1 / 279$ & $1 / 326$ & $1 / 239$ & $1 / 216$ & $1 / 266$ & $1 / 220$ & $1 / 191$ & $1 / 217$ \\
\hline & \begin{tabular}{|l|} 
Profundidade \\
de \\
carbonatação
\end{tabular} & $1 / 9,6$ & $1 / 5,5$ & $1 / 5,0$ & $1 / 7,7$ & $1 / 7,0$ & $1 / 7,6$ & $1 / 4,3$ & $1 / 6,0$ & $1 / 6,5$ & $1 / 6,7$ & $1 / 6,4$ & $1 / 5,8$ & $1 / 9,0$ \\
\hline & $\begin{array}{l}\text { Absorção de } \\
\text { água }\end{array}$ & $1 / 7,3$ & $1 / 6,9$ & $1 / 7,5$ & $1 / 7,3$ & $1 / 7,8$ & $1 / 11,2$ & $1 / 12,0$ & $1 / 7,3$ & $1 / 9,7$ & $1 / 11,4$ & $1 / 7,5$ & $1 / 8,0$ & $1 / 8,2$ \\
\hline & $\begin{array}{l}\text { Índice de } \\
\text { vazios }\end{array}$ & $1 / 16,0$ & $1 / 14,5$ & $1 / 17,5$ & $1 / 15,3$ & $1 / 14,9$ & $1 / 20,4$ & $1 / 23,1$ & $1 / 15,8$ & $1 / 20,2$ & $1 / 22,9$ & $1 / 15,9$ & $1 / 16,7$ & $1 / 19,0$ \\
\hline & Resistividade & 13,3 & 16,3 & 14,8 & 10,1 & 15,6 & 15,4 & 15,0 & 14,2 & 11,7 & 7,2 & 19,3 & 30,6 & 26,6 \\
\hline & $\begin{array}{l}\begin{array}{l}\text { Concentração } \\
\text { de cloretos }\end{array} \\
\end{array}$ & $1 / 0,50$ & 0,53 & $1 / 0,89$ & $1 / 0,44$ & $1 / 0,55$ & $1 / 0,54$ & $1 / 0,56$ & $1 / 0,61$ & $1 / 0,63$ & $1 / 0,59$ & $1 / 0,49$ & $1 / 0,54$ & $1 / 0,61$ \\
\hline & $\begin{array}{l}\text { Módulo de } \\
\text { elasticidade }\end{array}$ & 24,2 & 23,5 & 22,8 & 22,5 & 21,3 & 18,7 & 16,0 & 22,0 & 17,3 & 12,6 & 21,9 & 18,8 & 21,0 \\
\hline
\end{tabular}

Nota: resultados numéricos extraídos de Levy (2001).

Para verificar o desempenho relativo das alternativas, os dados da Tabela 7 foram normalizados. Para isso, os valores de cada quesito foram divididos pelo maior valor de cada linha. Esse artifício tem o objetivo de fazer com que todos os critérios considerados estejam na mesma escala, ou seja, variem de 0 a 1 . Esse detalhe possibilita o tratamento conjunto dos dados.
O índice de desempenho de cada combinação analisada é obtido multiplicando-se os valores normalizados de cada resultado de ensaio (Tabela 7) pela importância relativa de cada quesito analisado (Tabela 4). A partir de então, basta somar os valores de cada célula referente aos quesitos analisados de cada combinação entre agregados reciclados e agregados naturais. 
Tabela 7 - Resultados normalizados das alternativas usadas na AHP, para concretos de $20 \mathrm{MPa}$

\begin{tabular}{|c|c|c|c|c|c|c|c|c|c|c|c|c|c|c|}
\hline & \multirow[b]{2}{*}{$\begin{array}{c}\text { Dados gerais (normalizados) } \\
\text { de análise }\end{array}$} & \multicolumn{13}{|c|}{ Alternativas de escolhas } \\
\hline & & 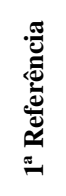 & 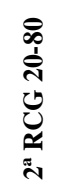 & 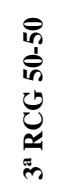 & 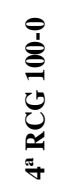 & 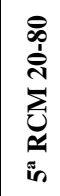 & 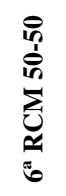 & 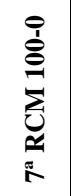 & 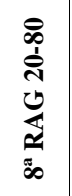 & 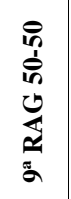 & 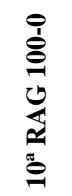 & 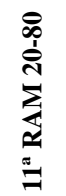 & 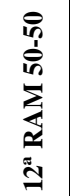 & 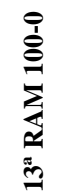 \\
\hline \multirow{8}{*}{ 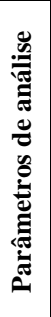 } & Relação água-cimento & 0,87 & 1,00 & 0,93 & 0,85 & 0,83 & 0,89 & 0,88 & 0,99 & 0,86 & 0,91 & 0,92 & 0,83 & 0,77 \\
\hline & Consumo de cimento por $\mathbf{m}^{3}$ & 1,00 & 0,67 & 0,77 & 0,94 & 0,90 & 0,64 & 0,55 & 0,75 & 0,83 & 0,67 & 0,81 & 0,94 & 0,82 \\
\hline & Profundidade de carbonatação & 0,45 & 0,78 & 0,86 & 0,56 & 0,61 & 0,57 & 1,00 & 0,72 & 0,66 & 0,64 & 0,67 & 0,74 & 0,48 \\
\hline & Absorção de água & 0,95 & 1,00 & 0,92 & 0,95 & 0,88 & 0,62 & 0,58 & 0,95 & 0,71 & 0,61 & 0,92 & 0,86 & 0,84 \\
\hline & Índice de vazios & 0,91 & 1,00 & 0,83 & 0,95 & 0,97 & 0,71 & 0,63 & 0,92 & 0,72 & 0,63 & 0,91 & 0,87 & 0,76 \\
\hline & Resistividade & 0,43 & 0,53 & 0,48 & 0,33 & 0,51 & 0,50 & 0,49 & 0,46 & 0,38 & 0,24 & 0,63 & 1,00 & 0,87 \\
\hline & Concentração de cloretos & 0,88 & 0,83 & 0,49 & 1,00 & 0,80 & 0,81 & 0,79 & 0,72 & 0,70 & 0,75 & 0,90 & 0,81 & 0,72 \\
\hline & Módulo de elasticidade & 1,00 & 0,97 & 0,94 & 0,93 & 0,88 & 0,77 & 0,66 & 0,91 & 0,71 & 0,52 & 0,90 & 0,78 & 0,87 \\
\hline
\end{tabular}

Nota: baseado nos dados de Levy (2001).

A melhor opção entre as combinações possíveis de agregados reciclados e agregados naturais é aquela que obtiver o maior índice de desempenho. Os resultados finais da Análise Hierárquica aplicada a agregados reciclados utilizados em concreto constam na Tabela 8.

Para o caso estudado, buscando-se um concreto com resistência de $20 \mathrm{MPa}$ e levando-se em consideração os critérios de durabilidade, as opções que apresentam os melhores índices de desempenho através da Análise Hierárquica são as opções 2 e 12. A opção 2 é referente a concretos produzidos com agregados graúdos com resíduos de concreto em uma proporção de $20 \%$ de agregado reciclado de concreto e $80 \%$ de agregados naturais. A opção 12 refere-se a concretos produzidos com substituição de $50 \%$ de agregado miúdo natural por agregado miúdo proveniente da reciclagem de produtos cerâmicos. Esperava-se que o concreto de referência apresentasse o maior índice de desempenho, pelo fato de o agregado reciclado ter características diferentes dos agregados naturais, o que supostamente afetaria negativamente sua durabilidade.

Partindo dessa questão, ao analisar os dados de entrada da Análise Hierárquica, pode-se verificar que em muitos critérios os concretos produzidos com agregados reciclados apresentaram eficiência superior aos concretos com agregados naturais. O concreto 2 com substituição de $20 \%$ de agregados graúdos naturais obteve uma relação água-cimento bem inferior ao concreto de referência, o que contribuiu para o desempenho observado. Analisando os índices do concreto de referência, verifica-se que os valores de resistividade para esse concreto foram baixos, além dos valores de profundidade de carbonatação, que foram muito superiores para ele.

\section{Concretos com fc $28 \mathrm{~d}$ de 30 e $40 \mathrm{MPa}$}

Com a finalidade de verificar se as alternativas de combinação de agregados reciclados obtidas para $20 \mathrm{MPa}$ mantêm-se caso seja necessário produzir concretos com 30 ou $40 \mathrm{MPa}$, aplicou-se a análise para os dados referentes a esses concretos. Os dados retirados também da tese de Levy (2001) constam nas Tabelas 5, 6 e 7. Os procedimentos de cálculos adotados na aplicação da Análise Hierárquica são os mesmos adotados para os concretos de $20 \mathrm{MPa}$ e já apresentados em etapas anteriores. Desse modo, para a otimização do espaço, optou-se por apresentar para essas duas classes de resistência apenas as tabelas finais de índice de desempenho (Tabela 9 para $30 \mathrm{MPa}$ e Tabela 10 para $40 \mathrm{MPa}$ ). 
Tabela 8 - Índices de desempenho para concretos de $20 \mathrm{MPa}$

\begin{tabular}{|c|c|c|c|c|c|c|c|c|c|c|c|c|c|c|}
\hline & & \multicolumn{13}{|c|}{ Alternativas de escolhas } \\
\hline & & 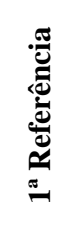 & 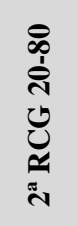 & 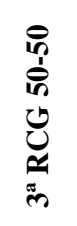 & 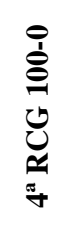 & 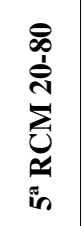 & 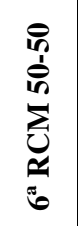 & 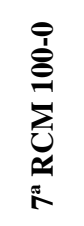 & 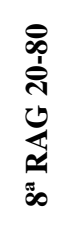 & 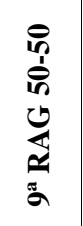 & 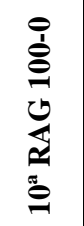 & 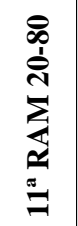 & 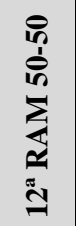 & 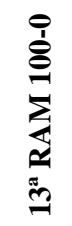 \\
\hline \multirow{8}{*}{ 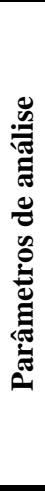 } & $\begin{array}{l}\text { Relação água- } \\
\text { cimento }\end{array}$ & 0,11 & 0,13 & 0,12 & 0,11 & 0,10 & 0,11 & 0,11 & 0,12 & 0,11 & 0,11 & 0,11 & 0,10 & 0,10 \\
\hline & $\begin{array}{l}\text { Consumo de cimento } \\
\text { por } \mathbf{m}^{3}\end{array}$ & 0,13 & 0,08 & 0,10 & 0,12 & 0,11 & 0,08 & 0,07 & 0,09 & 0,10 & 0,08 & 0,10 & 0,12 & 0,10 \\
\hline & $\begin{array}{l}\text { Profundidade de } \\
\text { carbonatação }\end{array}$ & 0,06 & 0,10 & 0,11 & 0,07 & 0,08 & 0,07 & 0,13 & 0,09 & 0,08 & 0,08 & 0,08 & 0,09 & 0,06 \\
\hline & Absorção de água & 0,12 & 0,13 & 0,12 & 0,12 & 0,11 & 0,08 & 0,07 & 0,12 & 0,09 & 0,08 & 0,12 & 0,11 & 0,11 \\
\hline & Índice de vazios & 0,11 & 0,13 & 0,10 & 0,12 & 0,12 & 0,09 & 0,08 & 0,11 & 0,09 & 0,08 & 0,11 & 0,11 & 0,10 \\
\hline & Resistividade & 0,05 & 0,07 & 0,06 & 0,04 & 0,06 & 0,06 & 0,06 & 0,06 & 0,05 & 0,03 & 0,08 & 0,13 & 0,11 \\
\hline & \begin{tabular}{|l|}
$\begin{array}{l}\text { Concentração de } \\
\text { cloretos }\end{array}$ \\
\end{tabular} & 0,11 & 0,10 & 0,06 & 0,13 & 0,10 & 0,10 & 0,10 & 0,09 & 0,09 & 0,09 & 0,11 & 0,10 & 0,09 \\
\hline & \begin{tabular}{|l|l|} 
Módulo de \\
elasticidade
\end{tabular} & 0,13 & 0,12 & 0,12 & 0,12 & 0,11 & 0,10 & 0,08 & 0,11 & 0,09 & 0,07 & 0,11 & 0,10 & 0,11 \\
\hline \multicolumn{2}{|r|}{ Índice de desempenho } & $\mathbf{0 , 8 1}$ & 0,85 & 0,78 & $\mathbf{0 , 8 1}$ & $\mathbf{0 , 8 0}$ & 0,69 & $\mathbf{0 , 7 0}$ & $\mathbf{0 , 8 0}$ & $\mathbf{0 , 7 0}$ & 0,62 & 0,83 & 0,85 & 0,77 \\
\hline
\end{tabular}

Tabela 9 - Índices de desempenho para concretos de $30 \mathrm{MPa}$

\begin{tabular}{|c|c|c|c|c|c|c|c|c|c|c|c|c|c|c|}
\hline & & \multicolumn{13}{|c|}{ Alternativas de escolhas } \\
\hline & & 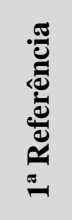 & 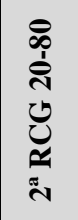 & 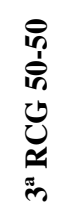 & 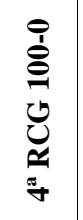 & 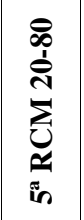 & 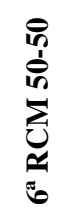 & 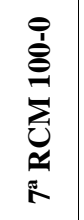 & 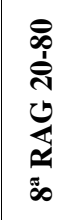 & 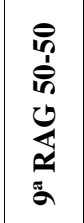 & 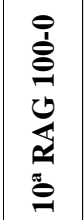 & 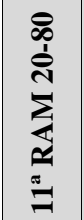 & 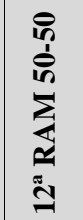 & 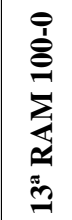 \\
\hline \multirow{8}{*}{ 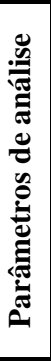 } & Relação água-cimento & 0,68 & 0,63 & 0,65 & 0,71 & 0,69 & 0,63 & 0,58 & 0,66 & 0,69 & 0,68 & 0,65 & 0,73 & 0,76 \\
\hline & Consumo de cimento por $\mathbf{m}^{3}$ & 291 & 341 & 329 & 293 & 333 & 417 & 522 & 325 & 330 & 366 & 329 & 300 & 332 \\
\hline & $\begin{array}{l}\text { Profundidade de } \\
\text { carbonatação }\end{array}$ & 6 & 3,9 & 3,4 & 5,2 & 4,2 & 3,4 & 0,2 & 4,6 & 4,6 & 4,9 & 4,3 & 4 & 5,8 \\
\hline & Absorção de água & 6,6 & 6,3 & 7 & 8 & 7,6 & 9,5 & 11,7 & 7,2 & 9 & 10,7 & 6,9 & 7,6 & 8,9 \\
\hline & Índice de vazios & 14,6 & 13,5 & 17,3 & 16,8 & 13,5 & 19,5 & 22,8 & 15,7 & 19 & 21,7 & 15,1 & 16,2 & 18,6 \\
\hline & Resistividade & 17 & 17,9 & 16,9 & 12,1 & 18 & 15,8 & 11 & 15 & 10,7 & 7,4 & 18,3 & 26,8 & 23,9 \\
\hline & Concentração de cloretos & 0,41 & 0,47 & 0,67 & 0,37 & 0,45 & 0,51 & 0,52 & 0,48 & 0,57 & 0,6 & 0,43 & 0,47 & 0,56 \\
\hline & Módulo de elasticidade & 27 & 26,6 & 25,7 & 25,1 & 23,6 & 21,7 & 19,6 & 25,4 & 21 & 17,3 & 25 & 22,3 & 23,7 \\
\hline \multicolumn{2}{|c|}{ Índice de desempenho total } & 0,79 & 0,78 & 0,71 & 0,73 & 0,74 & 0,64 & 0,69 & 0,73 & 0,63 & 0,55 & 0,76 & 0,76 & 0,69 \\
\hline
\end{tabular}




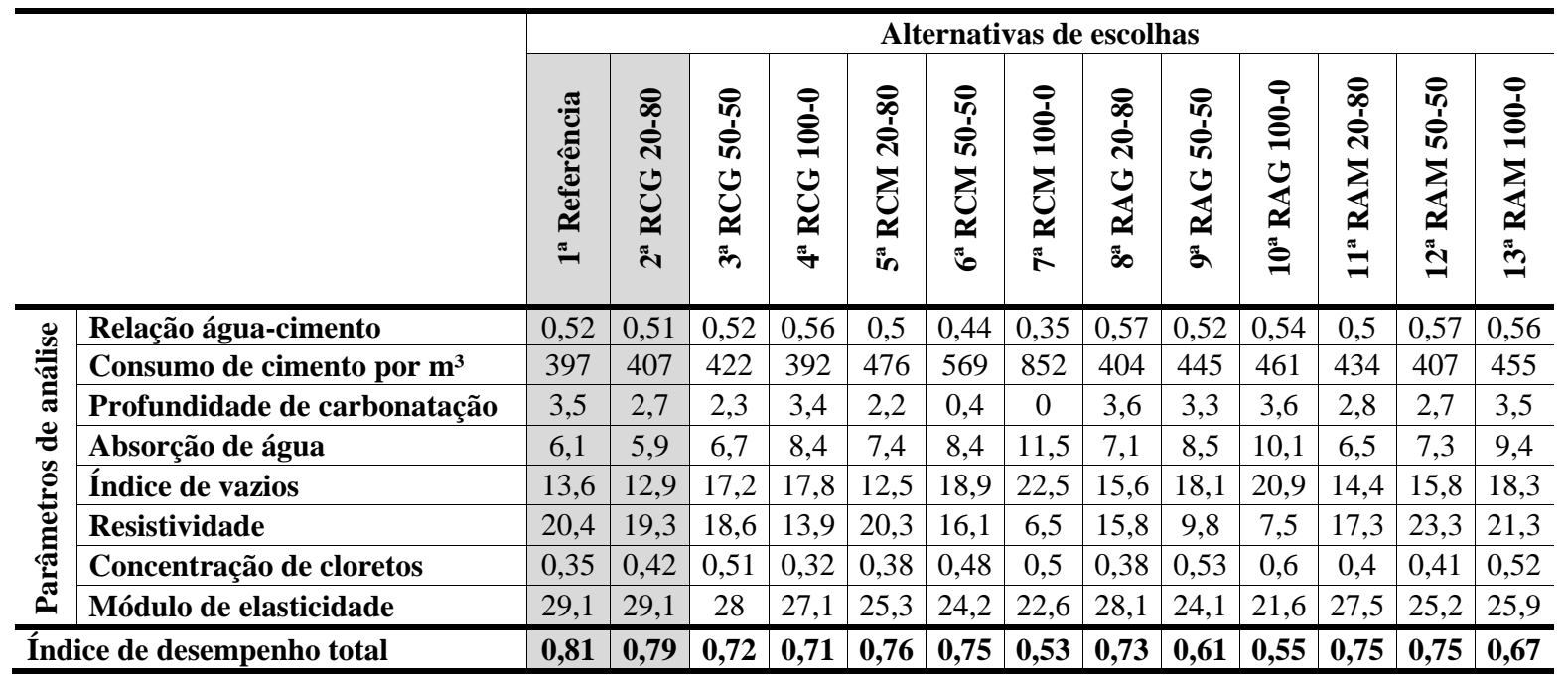

Nota: baseado nos dados de Levy (2001).

Diferentemente do concreto de $20 \mathrm{MPa}$, para os concretos de $30 \mathrm{MPa}$ o concreto de referência obteve o maior índice de desempenho, juntamente com a opção 2, que se manteve entre as escolhidas, e as opções 11 e 12. A melhora no desempenho obtido pelo concreto de referência pode ser atribuída à equiparação das relações água-cimento entre as variáveis. Verifica-se também que, apesar da melhora relativa nos índices para esse concreto, a variável profundidade de carbonatação continua com índices elevados. Isso não chegou a comprometer o desempenho dessa variável, pois o consumo de cimento significativamente menor pareceu compensar as outras variáveis deficientes.

Para a opção 11 a relação água-cimento baixa parece ter sido a principal responsável pelo elevado índice de desempenho obtido. Contribuindo para a escolha da opção 11 tem-se a absorção de água, a resistividade, o teor de cloretos e o módulo de elasticidade, que, mesmo não apresentando grande diferença no valor quando comparado com as outras opções, somados, contribuíram para o aumento no índice de desempenho dessa opção.

O baixo consumo de cimento, o menor entre as opções com a incorporação de material reciclado, parece ter sido o principal responsável pela escolha da opção 12. A alta resistividade e a baixa concentração de cloretos também contribuíram, ainda que em menor escala. A opção 2 manteve-se entre as escolhidas, principalmente devido à redução na relação a/c, profundidade de carbonatação e concentração de cloretos.

Observando-se os resultados, verifica-se consistência nos índices obtidos. É fato que tanto para os concretos de $30 \mathrm{MPa}$ quanto para os de 40 $\mathrm{MPa}$ as opções 1 e 2 mantiveram-se com os maiores índices de desempenho. A primeira opção é o próprio concreto de referência, no qual não houve substituição de agregados naturais por agregados reciclados. A segunda opção é a de concretos produzidos com resíduos de concreto nas frações graúdas em uma proporção de $20 \%$ de agregados reciclados.

Mantendo o foco nessas duas opções, elaborou-se a Tabela 11, que apresenta uma comparação entre as diferentes classes de resistência de concreto para as duas opções indicadas pela Análise Hierárquica.

O concreto de referência não foi escolhido como opção para concretos de $20 \mathrm{MPa}$. Isso parece ter sido consequência principalmente da elevada relação água-cimento apresentada por esse concreto $(\mathrm{a} / \mathrm{c}=0,91)$, sendo esse critério contornado para os concretos de resistências superiores $(\mathrm{a} / \mathrm{c}=0,68$ e 0,52$)$. Para os outros parâmetros, as mudanças parecem ter sido mais suaves com a mudança de classes de resistência, porém sempre mantendo o aumento na qualidade dos dados, com vistas à durabilidade. 
Tabela 11 - Comparação entre as diferentes classes de concreto

\begin{tabular}{|c|c|c|c|c|c|c|}
\hline \multirow{2}{*}{ Desempenho } & \multicolumn{3}{|c|}{$1^{\text {a }}$ Referência 0-100 } & \multicolumn{3}{|c|}{$2^{\text {a }}$ RCG 20-80 } \\
\hline & $20 \mathrm{MPa}$ & $30 \mathrm{MPa}$ & $40 \mathrm{MPa}$ & $20 \mathrm{MPa}$ & $30 \mathrm{MPa}$ & $40 \mathrm{MPa}$ \\
\hline Relação água-cimento & 0,91 & 0,68 & 0,52 & 0,79 & 0,63 & 0,51 \\
\hline Consumo de cimento por $\mathbf{m}^{3}$ & 179 & 291 & 397 & 269 & 341 & 407 \\
\hline Profundidade de carbonatação & 9,6 & 6,0 & 3,5 & 5,5 & 3,9 & 2,7 \\
\hline Absorção de água & 7,3 & 6,6 & 6,1 & 6,9 & 6,3 & 5,9 \\
\hline Índice de vazios & 16,0 & 14,6 & 13,6 & 14,5 & 13,5 & 12,9 \\
\hline Resistividade & 13,3 & 17,0 & 20,4 & 16,3 & 17,9 & 19,3 \\
\hline Concentração de cloretos & 0,50 & 0,41 & 0,35 & 0,53 & 0,47 & 0,42 \\
\hline Módulo de elasticidade & 24,2 & 27,0 & 29,1 & 23,5 & 26,6 & 29,1 \\
\hline
\end{tabular}

Como este trabalho utiliza os dados da tese de Levy (2001) e esta desenvolveu-se no período de 1999 a 2000, o trabalho seguiu a NBR 6118 (ANBT, 1980), sendo o fck mínimo permitido de $18 \mathrm{MPa}$. O autor optou pelo estudo de concretos com fck mínimo de $20 \mathrm{MPa}$ por este ser largamente utilizado na maioria das pequenas obras do território nacional e pelo fato de o foco principal de seu trabalho ter sido a determinação das propriedades que mais influem na durabilidade de concretos. Vale destacar que um concreto com fcj igual a $20 \mathrm{MPa}$ não é de uso permitido pela NBR 6118 (ABNT, 2007) em aplicações estruturais, uma vez que o fck mínimo preconizado nesse documento é $20 \mathrm{MPa}$, o qual, considerando o Sd, resultará em um concreto com fcj necessariamente superior a $20 \mathrm{MPa}$. Por outro lado, a NBR 15116 (ABNT, 2004) prevê a utilização de agregados reciclados sem fins estruturais, e os concretos de $20 \mathrm{MPa}$ seriam uma excelente opção para essas aplicações.

Para os concretos fabricados com as proporções da segunda opção, que foi escolhido em todas as classes de concreto estudadas, verifica-se que as mudanças na classe de resistência resultaram em efeitos relativamente proporcionais e a favor da durabilidade do concreto.

\section{Conclusões}

A Análise Hierárquica é uma importante ferramenta de auxílio à decisão, a qual possibilita o reconhecimento da subjetividade inerente aos processos decisórios. No AHP os resultados são apresentados sob a forma de prioridades. Isso permite que se possa avaliar o quanto uma alternativa é superior a outra por um ponto de vista global. A qualidade dos resultados obtidos depende da qualidade da modelagem e das avaliações envolvidas, por isso o objetivo da análise deve ser claro. Na utilização dessa ferramenta o problema é modelado pela construção de hierarquias, nas quais são considerados múltiplos critérios de decisão.
Quanto às combinações entre agregados reciclados e agregados naturais, as proporções que se mostraram mais eficientes para produção de concretos de $20 \mathrm{MPa}$ foram as referentes a concretos produzidos com agregados graúdos de resíduos de concreto em uma proporção de 20:80; e para concretos produzidos com substituição de agregado miúdo natural por agregado miúdo proveniente da reciclagem de produtos cerâmicos nas proporções de 50:50, as opções 2 e 12 respectivamente. Para os concretos de $30 \mathrm{MPa} o$ concreto de referência aparece entre as opções escolhidas juntamente com a opção 11, além da manutenção das opções 2 e 12.

Para concretos com 40 MPa houve prevalência na utilização de agregados reciclados de concreto, sendo as opções 1, 2 as recomendadas. É importante salientar que, no caso de concretos com fcj de $20 \mathrm{MPa}$, esse nível de resistência não representa concretos estruturais de acordo com a NBR 6118 (ABNT, 2007), pois o menor nível de fck preconizado na referida norma para uso estrutural é $20 \mathrm{MPa}$.

Em muitos critérios analisados, os concretos produzidos com agregados reciclados apresentaram desempenho superior aos concretos com agregados naturais. O desempenho dos concretos quanto à durabilidade melhoram com o aumento das resistências, devido principalmente à diminuição da relação a/c. Valores de resistividade e profundidade de carbonatação parecem ter sido decisivos.

A Análise Hierárquica mostrou-se adequada para a sistematização de escolhas na área de concretos com agregados reciclados. Os fatores a serem considerados e seus devidos pesos são pontos a serem discutidos em trabalhos futuros para 0 aprimoramento do método proposto neste trabalho. 


\section{Referências}

AMERICAM SOCIETY FOR TESTING AND MATERIALS. ASTM E 1765: standard practice for applying analytical hierarchy process (AHP) to multiattribute decision analysis of investments related to buildings and buildings systems. 2002.

\section{ASSOCIAÇÃO BRASILEIRA DE NORMAS} TÉCNICAS. NBR 6118: projeto de estruturas de concreto: procedimento. Rio de Janeiro, 1980.

ASSOCIAÇÃO BRASILEIRA DE NORMAS TÉCNICAS. NBR 6118: projeto de estruturas de concreto: procedimento. Rio de Janeiro, 2007.

ASSOCIAÇÃO BRASILEIRA DE NORMAS TÉCNICAS. NBR 15116: agregados reciclados de resíduos sólidos da construção civil: utilização em pavimentação e preparo de concreto sem função estrutural: requisitos. Rio de Janeiro, 2004.

AWASTHI, A.; CHAUHAN, S. S. Using AHP and Dempster e Shafer Theory For Evaluating Sustainable Transport. Environmental Modeling and Software, v. 26, n. 6, p. 787-796, jun. 2011.

COSTA, H. G. Introdução ao Método de Análise Hierárquica: análise multicritério no auxílio à decisão. Niterói, RJ: 2002.

EVANGELISTA, L.; BRITO, J. de. Durability Performance of Concrete Made With Fine Recycled Concrete Aggregates. Cement and Concrete Composites, v. 32, n. 1, p. 9-14, jan. 2010.

HANSEN, T. C. Recycling of Demolished Concrete and Masonry. London: E\&FN Spon, 1992.

HELENE, P. L.; TERZIAN, P. Manual de Dosagem e Controle do Concreto. São Paulo: PINI, 1993.
ISSAI, M. T. et al. Intelligent Timetable Evaluation Using Fuzzy AHP. Expert Systems with Applications, v. 38, n. 4, p. 3718-3723, abr. 2011.

LEITE, M. B. Avaliação de Propriedades Mecânicas de Concretos Produzidos Com Agregados Reciclados de Resíduos de Construção e Demolição. Porto Alegre, 2001. Tese (Doutorado em Engenharia Civil) - Escola de Engenharia, Universidade Federal do Rio Grande do Sul, Porto Alegre, 2001.

\section{LEVY, S. M. Contribuição ao Estudo da} Durabilidade de Concretos, Produzidos com Resíduos de Concreto e Alvenaria. São Paulo. 2001. Tese (Doutorado em Engenharia Civil) Escola Politécnica, Universidade de São Paulo, São Paulo, 2001.

VIEIRA, G. L.; DAL MOLIN, D. C. C.; LIMA, F. B. Resistência e Durabilidade de Concretos Produzidos Com Agregados Reciclados Provenientes de Resíduos de Construção e Demolição. Revista Engenharia Civil da Universidade do Minho, v. 19, p. 5-18, 2004.

PINTO, T. P. P. Metodologia Para a Gestão Diferenciada de Resíduos Sólidos da Construção Urbana. 190 f. São Paulo. 1999. Tese (Doutorado em Engenharia Civil) - Escola Politécnica, Universidade de São Paulo, São Paulo, 1999.

TAM, V. W. Y.; TAM, C. M.; WANG, Y. Optimization on Proportion For Recycled Aggregate in Concrete Using Two-Stage Mixing Approach. Construction and Building Materials, v. 21, n. 10, p. 1928-1939, out. 2006.

VIDAL, L. A. et al. Applying AHP to Select Drugs To Be Produced by Anticipation in A Chemotherapy Compounding Unit. Expert Systems with Applications, v. 37, n. 2, p. 15281534, mar. 2010.

Revista Ambiente Construído

Associação Nacional de Tecnologia do Ambiente Construído

Av. Osvaldo Aranha, 99 - 3o andar, Centro

Porto Alegre - RS - Brasil CEP $90035-190$

Telefone: +55 (51) 3308-4084 Fax: +55 (51) 3308-4054

www. seer. ufrgs. br/ ambienteconstruido

E-mail: ambienteconstruido@ufrgs.br

134 Pereira, E.; Medeiros, M. H. F. de; Levy, S. M. 